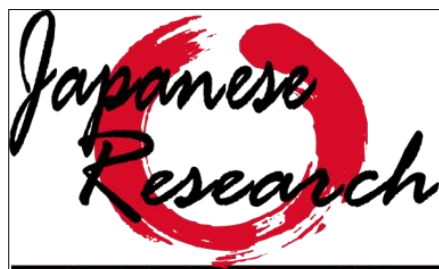

on Linguistics, Literature, and Culture
Japanese Research on Linguistics, Literature, and Culture

Vol. 1 No. 1 Nov. 2018, Hal. 79-91, ISSN: 2655-4836

https://publikasi.dinus.ac.id/index.php/irllc/article/view/2129/1383

Published by Universitas Dian Nuswantoro,

Jl. Imam Bonjol 207, Semarang

\title{
Nilai Filosofis dalam Chanoyu
}

\author{
Teti Indriati Kastuti
}

Universitas Teknologi Yogyakarta

tetiindriati@uty.ac.id

Article History: Submitted date 2018-11-17; Accepted date 2018-11-30; Published date 2018-11-30

\begin{abstract}
This research is entitled Philosophical Value in Chanoyu. There are three problems formulated in this research, as follows; 1) Is there any philosophical value in Chanoyu? 2) How is philosophical value in seven rules of Sen no Rikyu (shichisoku), 3) How is philosophical value in four basic spiritual principles of Sen no Rikyu?. This research aims 1) to find out the illustration of philosophical value in Chanoyu, 2)to find out the illustration of philosophical value in seven rules of Sen no Rikyu, 3) to find out the illustration of philosophical value infour basic spiritual principles of Sen no Rikyu (shiki). This research employs descriptive method by developing data and real fact and literature method by using data from the available literature. The research results conclude that there are philosophical values in Chanoyu, philosophical value in seven rules of Sen no Rikyu and four basic spiritual principles of Sen no Rikyu are the basis of the highest idealism in the practice of Chanoyu.
\end{abstract}

Keyword: chanoyu, philosophical value, shichisoku, shiki 


\begin{abstract}
Abstrak
Penelitian ini berjudul "Nilai Filosofis dalam Chanoyu". Dalam penelitian ini permasalahan dirumuskan adalah benarkah ada nilai filosofis dalam Chanoyu, bagaimana nilai filosofis dalam tujuh aturan Sen no Rikyu (shichisoku), bagaimana nilai filosofis dalam empat prinsip dasar spiritual Sen no Rikyu. Penelitian ini bertujuan 1) untuk memperoleh gambaran tentang nilai filosofis dalam chanoyu; 2) untuk memperoleh gambaran nilai filosofis dalam tujuh aturan Sen no Rikyu (shichisoku); 3) untuk memperoleh gambaran nilai filosofis dalam empat prinsip dasar spiritual (shiki) Sen no Rikyu. Metode penelitian yang digunakan adalah metode deskriptif, yaitu dengan mengembangkan data dan fakta seperti yang ada sebenarnya serta metode kepustakaan dengan menggunakan data dari pustaka yang ada. Dari hasil penelitian diperoleh simpulan bahwa dalam Chanoyu terdapat nilai-nilai filosofis, nilai-nilai filosofis dalam tujuh aturan dan empat dasar spiritual Sen no Rikyu merupakan dasar idealisme tertinggi dalam praktik chanoyu.
\end{abstract}

Kata kunci: chanoyu, nilai filosofis, shichisoku, shiki

\title{
1. Pendahuluan
}

Proses studi atau proses berfilsafat dimulai dengan ketakjuban, ketidak puasan, hasrat bertanya, dan keraguan seseorang filsuf terhadap sesuatu yang dialaminya. Sehubungan dengan itu dalam berfilsafat para filsuf tidak berpikir dengan bertolak kepada suatu asumsi yang telah ada, sebaliknya mereka menguji asumsi yang telah ada. Selain itu, berpikir filosofis atau berfilsafat bersifat kontemplatif, artinya berpikir untuk mengungkap hakikat dari sesuatu yang dipikirkan, atau berpikir spekulatif yakni berpikir melampauai fakta yang ada untuk mengungkap apa yang ada di balik yang nampak, atau disebut pula berpikir radikal, yaitu berpikir sampai kepada akar dari sesuatu yang dipertanyakan hingga terungkap hakikat dari apa yang dipertanyakan tersebut. Adapun dalam rangka mengungkap hakikat sesuatu yang dipertanyakannya itu para filsuf berpikir secara sinoptik, yaitu berfikir dengan pola yang bersifat merangkum keseluruhan tentang apa yang sedang dipikirkan atau dipertanyakan, pola berpikir ini merupakan kebalikan dari pola berpikir analitik. Perlu dipahami pula bahwa dalam berpikirnya itu para filsuf melibatkan seluruh pengalaman insaninya sehingga bersifat subjektif. Kata filsafat dijabarkan dari perkataan philosophia. Perkataan itu berasal dari bahasa Yunani yang berarti cinta akan kebijaksanaan (love of wisdom). Pythagoras atau Sokrateslah yang pertama-tama menyebut diri Philosophus, pecinta kebijaksanaan, artinya orang yang ingin 
mempunyai pengetahuan yang luhur (sophia); mengingat keluhuran pengetahuan yang dikejarnya itu, maka orang tidak mau berkata bahwa telah mempunyai, memiliki, dan menguasainya (Driyarkara, 2006). Suseno menyatakan berfilsafat bergulat dengan masalahmasalah dasar manusia, cenderung, mempertanyakan apa saja secara kritis dari seluruh realitas kehidupan (Suseno, 1992). Hakikatnya filsafat membantu masyarakat dalam memecahkan masalah-masalah kehidupan. Filsafat dapat dipandang sebagai usaha manusia untuk menangani pertanyaan-pertanyaan fundamental tersebut secara bertanggung jawab. Filsafat menjadi suatu ajaran hidup. Orang mengharapkan dari filsafat dasar-dasar ilmiah yang dibutuhkan untuk hidup. Filsafat diharapkan memberikan petunjuk-petunjuk bagaimana kita harus hidup untuk menjadi manusia yang sempurna, yang baik, yang susila, dan bahagia. Jadi, tidak hanya ilmu yang teoretis saja, melainkan yang praktis juga, artinya yang mencoba menyusun aturan-aturan yang harus dituruti agar hidup kita mendapat isi dan nilai. Dan ini sesuai dengan arti filsafat sebagai usaha mencari kebijaksanaan yang meliputi pengetahuan (insight) maupun sikap hidup yang benar-benar, yang sesuai dengan pengetahuan itu.

Chanoyu dilihat dari karakter huruf kanjinya terdiri dari huruf-huruf sebagai berikut cha (茶) artinya teh, no (の) sebagai partikel penghubung, dan yu(湯) air hangat atau air panas. Arti kata chanoyu secara harafiah adalah "air panas untuk teh". Chanoyu mempunyai nama lain yakni chado (茶道) yang berarti “cara pembuatan teh”, namun kemudian berkembang lebih luas menjadi upacara minum teh dalam tradisi Jepang. Sen Rikyu mengatakan" yang disebut chanoyu hanyalah merupakan tindakan menjerang air, membuat teh, lalu meminumnya” (納屋, 1997). Dengan kata lain bagi yang berniat menggeluti cha no michi (chado) kata serius dan bersungguh-sungguh merupakan kata yang penting. Artinya yang disebut chado itu adalah sesuatu yang mengandung segala aspek hidup dan kehidupan di dalamnya, kita akan tahu makhluk seperti apa kita ini, sehingga bisa memahami diri kita sendiri bersamaan dengan itu kesadaran bahwa hidup tidak sendirian tetapi bersama orang lain semakin jelas.

Filosofi yang mendasari upacara minum teh berasal dari ajaran Budhis Zen. Zen merupakan istilah Jepang yang dalam bahasa China adalah chan. Kata chan sendiri merupakan terjemahan dari kata dalam bahasa Sansakerta dhyana yang berarti meditasi dengan tujuan memperoleh wawasan spiritual yang mendalam. Baik teh maupun zen menekankan sebuah 
cara melatih tubuh dan pikiran dengan jalan disiplin spiritual yang ketat. Teh bukan hanya dituang dengan air panas dan diminum tetapi sebagai seni dalam arti luas. Upacara ini sebenarnya merupakan suatu metode yang mempunyai struktur sangat rumit dalam menyiapkan minuman yang terbuat dari serbuk teh, untuk disajikan kepada kelompok tamu yang dihormati. Upacara minum teh Jepang ini menyangkut unsur-unsur lain dari kesenian seperti kesenian keramik dalam penggunaan perabot tumah minum dan makan, juga seni menata taman dan seni arsitektur yang berfungsi dalam penataan tempat upacara tersebut. Upacara minum teh mencerminkan kepribadian dan pengetahuan tuan rumah yang mencakup antara lain tujuan hidup, cara berpikir, agama, apresiasi peralatan upacara minum teh dan cara meletakkan benda seni di dalam ruangan upacara minum teh (chashitsu) dan berbagai pengetahuan seni secara umum yang bergantung pada aliran upacara minum teh yang dianut (Plutschow, 1986).

Dengan penekanannya pada disiplin mental dan psikis, upacara minum teh terlebih mengarah pada pelampuan dualisme yang memisahkan dunia luar dan dalam manusia, yang biasa disebut pula sifat subjektif dan objektif. Upacara ini membangun interaksi antara bahasa dan kesunyian, juga logika dan emosi untuk menjembatani jarak yang memisahkan manusia dengan alam semestanya. Pada intinya, upacara ini bertujuan untuk meninggalkan batasanbatasan dari dalam diri. Oleh karena itu, berlatih upacara minum teh merupakan bentuk pendisiplinan diri yang memiliki latar belakang nilai religius yang tinggi. Karena baik pikiran dan tubuh harus tunduk terhadap disiplin tersebut, tidak mengejutkan jika upacara ini perlu waktu yang sangat lama untuk dikuasai. Teh bukan hanya teknik atau sebuah kesenian, tetapi merupakan sebuah jalan kehidupan.

Upacara minum teh menyatukan tradisi-tradisi filosofis dn artistik Jepang dari berbagai sumber dan masa. Sadler mengungkapkan "chanoyu memang dapat dikatakan sebagai sebuah contoh dari kehidupan bermasyarakat Jepang. Hal ini dikarenakan perpaduannya yang seimbang dari elemen-elemen yang diambil dari budaya-budaya tertua timur". Inilah yang menjadi alasan kenapa banyak orang Jepang menganggap upacara minum teh merupakan sesuatu yang khas Jepang dan tidak ditemukan di tempat lain. Semua gerakan dalam upacara minum dimaksudkan untuk menciptakan harmoni, kesucian, penghargaan diri, dan kedamaian. 
Genshitsu Sen menyatakan tujuan chanoyu adalah untuk mengajari kita ketenangan pikiran dalam keadaan apapun, tidak pernah takut atau bingung dengan hal yang mungkin terjadi (Sen, Genshitsu, \& Soushitsu, 2004). Chanoyu memberi kita kemampuan untuk menghadapi dengan siap dan tenang, perkembangan teknologi informasi dan perubahan masyarakat yang kerap kali mengejutkan. Hal ini merupakan kemampuan dan kebijaksanaan yang kita peroleh lewat pelatihan mendalam pada tubuh dan pikiran lewat praktik chanoyu.

Keluasan dan kedalaman makna chanoyu sebagaimana dijelaskan di atas, menunjukkan bahwa chanoyu merupakan hasil kebudayaan masyarakat Jepang yang mengandung ajaran yang dapat memberi petunjuk-petunjuk bagaimana seseorang harus hidup untuk menjadi manusia yang baik, mempunyai harga diri dan memperoleh kedamaian. Dalam penelitian ini, chanoyu dikaji dari sudut pandang filsafat sebagai ajaran hidup. Secara khusus, penelitian ini bertujuan untuk menggali dan merumuskan nilai filosofis dari tujuh aturan dan empat dasar aturan Sen Rikyu.

\section{Metode Penelitian}

Penelitian ini menggunakan metode deskriptif kualitatif. Materi atau bahan penelitian ini berupa bahan kepustakaan, yaitu (1) Historical Chanoyu karangan Herbert E. Plutschow, diterbitkan oleh The Japan Time, Tokyo, (2) Urasenke Chado Textbook, supervising editor Genshitsu Sen dan Soshitsu Sen, diterbitkan oleh Tankosha, (3) 初めてのお茶のたて方、 menguraikan langkah-langkah awal memasuki prosedur chanoyu (Sen et al., 2004), (4) Pemahaman Makna Chado dengan Dasar Spiritual Senrikyu melalui Bonryakutemae, jurnal Sastra Jepang (Kastuti, 2010). Langkah-langkah penelitian yang dilakukan adalah pengumpulan data, display data, dan penarikan kesimpulan. Analisis data menggunakan metode hermeneutika dan heuristika.

\section{Hasil dan Pembahasan}

\subsection{Budaya dan Nilai Filosofis dalam Chanoyu}

Kebudayaan adalah keseluruhan sistem gagasan, tindakan, dan hasil karya manusia dalam rangka kehidupan masyarakat yang dijadikan milik diri manusia dengan belajar 
(Koentjaraningat, 1979). Kebudayaan berasal dari kata Sansekerta buddhayah, yang merupakan bentuk jamak dari buddhi yang berarti budi atau akal. Dengan demikian kebudayan dapat diartikan hal-hal yang bersangkutan dengan akal (Koentjaraningat, 1979). Salah satu kebudayaan Jepang yang menjadi tradisi dalam masyarakat Jepang hingga saat ini adalah chanoyu. Sedangkan menurut Liu Tong, Tea is a tradition of life as well as of culture (Somantri, 2014). Somantri menyatakan bahwa filosofi yang terkandung di dalam upacara minum teh Jepang mencakup antara lain tujuan hidup, cara berpikir, apresiasi peralatan upacara minum teh, dan cara meletakkan benda seni di dalam ruangan upacara minum teh (Somantri, 2014).

Genshitsu Sen yang menyatakan bahwa filosofi Chanoyu/chadou dapat dimaknai sebagai sebuah studi dalam tiga bentuk: lewat disiplin pikiran, perolehan pengetahuan dan latihan (Sen et al., 2004). Ada beberapa hal penting yang harus diperhatikan; 1) studi chanoyu mampu memperluas kemampuan seseorang untuk menjamu tamu. li Naosuke, penasihat tetua di masa-masa akhir pemerintahan Tokugawa shogunate, merupakan praktisi chanoyu yang tekun dan sempat membuat sebuah buku berjudul "Chanoyu Ichie Shuu". la menekankan hubungan orang-orang yang berkumpul saat chanoyu sebagai sebuah kejadian yang "terjadi sekali seumur hidup", yang ia jelaskan sebagai "ichigo ichie". Dalam hal ini chanoyu berdasarkan pada semangat "ichigo ichie" yang berarti "menghargai tiap momen". 2) Gerakan-gerakan chanoyu yang notebene gerakan dasar sehari-hari, dibuat indah dalam praktiknya. Aisatsu: gestur, frasa, dan ungkapan formal yang merupakan bagian pembentuk chanoyu. Aisatsu seperti gerakan membungkuk, dan mengucapkan osakini, 3) Konfusianisme, merupakan sistem pengajaran etika yang digagas oleh filsuf dan guru China, yang dikenal dengan gojou: jin (kebaikan), gi (kebenaran), rei (kesopanan), chi (kebijaksanaan), dan shin (kesetiaan), 4) chanoyu membantu kita memperbaiki sensibilitas terhadap keindahan. 5) daya tarik teh adalah dampak baiknya terhadap kesehatan tubuh dan jiwa. Kissa Youjou Ki yang ditulis oleh Eisai Zenji, 6) ichiza konryuu: secara bahasa, frasa ini berarti "membangun posisi", yang berarti atmosfir kebersamaan dibangun lewat interaksi antara penjamu dengan tamu-tamunya, 7) chanoyu didasarkan pada nilai saling menghargai yang sejalan dengan semangat ichiza konryuu, yakni semangat kerjasama dan pertalian antar sesama demi menciptakan suatu kesatuan ketika 
mereka bersama, 8) kita perlu mengetahui tujuan utama dari chadou yang berhubungan dengan bagaimana kita harus menjalani kehidupan kita sebagai seorang manusia.

\subsection{Tujuh Ajaran Etika Moral SennoRikyu (shichisoku)}

Etika sering diidentikkan dengan moral (atau moralitas). Namun, meskipun sama-sama terkait dengan baik-buruk tindakan manusia, etika dan moral memiliki perbedaan pengertian. Moralitas lebih condong pada pengertian nilai baik dan buruk dari setiap perbuatan manusia itu sendiri, sedangkan etika berarti ilmu yang mempelajari tentang baik dan buruk. Jadi bisa dikatakan etika berfungsi sebagai teori tentang perbuatan baik dan buruk. Dalam filsafat etika terkadang disamakan dengan filsafat moral (Haidar, 2005). Menurut hukum etika suatu perbuatan itu dinilai dari 3 tingkat, yaitu :

a. Tingkat pertama: semasa belum lahir menjadi perbuatan, yakni berupa rencana dalam hati atau niat;

b. Tingkat kedua: perbuatan nyata atau pekerti;

c. Tingkat ketiga: akibat atau hasil dari perbuatannya itu (Burhanuddin, 2000).

Chanoyu dalam praktiknya memerlukan tahapan-tahapan berupa etika moral yang diajarkan oleh SenRikyu. Dalam buku Urasenke Chado Texbook diceritakan seorang murid Rikyu suatu hari pernah bertanya tentang hal yang paling penting diingat dalam chanoyu. Rikyu menjawab, "Buatlah secawan teh yang memuaskan, tempatkan arang dengan baik agar air yang direbus matang dengan baik, tata bunga-bunga sebagaimana mereka di alam bebas, ciptakan suasana sejuk saat musim panas dan hangat saat musim dingin, selalu berjaga-jaga dalam segala hal, bersiap jika hujan datang, dan selalu memperhatikan tamu-tamu yang hadir. " Pendeta Shourei, yang saat itu juga mendengar perbincangan tersebut mendukung jawaban Rikyuu. la mengucap ajaran master Zen bernama Chouka yang berbunyi "Jangan kau melakukan hal buruk, tapi lakukan lah hal baik." Jika dipikir lagi seorang anak kecil pun tahu hal itu, tapi untuk melakukannya lain lagi. Bahkan seorang berumur 80 tahun pun belum tentu bisa benarbenar mempraktikannya. Percakapan ini merupakan dialog yang tercatat dalam Nanpouroku. Ketika pertanyaan si murid akhirnya terjawab, semua orang dalam ruangan pun tersadar jika mereka harus terus berusaha melakukan kebaikan dan menjauhi keburukan. Bahkan anak kecil pun tahu hal ini karena sudah diajarkan sejak kecil. Namun terkadang, hal yang kita sudah tahu 
dan terdengar mudah pun sulit untuk dilakukan. Intinya adalah bahwa memahami saja tujuh aturan Rikyu tidak cukup. Kita harus memahami bahwa ada implikasi mendalam di balik katakata tersebut, yang menjadi alasan kenapa ajaran Rikyu diwariskan dari generasi ke generasi tanpa mengalami perubahan dalam prinsip fundamental dan Jalan Hidup Tehnya. Dengan memahami implikasi mendalam di balik ajaran-ajaran ini, seseorang akan menyadari bahwa chanoyu merupakan suatu sistem budaya yang memiliki nilai moral dan etika yang tinggi, tidak seperti pertunjukkan artistik lain.

Makna dibalik tujuh ajaran etika/moral Rikyu (納屋, 1997) yaitu:

\subsection{1. 茶は服のよきように点て Teh itu dibuat supaya enak’}

Makna kalimat itu sederhana, buatlah teh yang enak. Namun, teh yang enak saja tidak cukup untuk menjadikannya memuaskan. Bahkan, walaupun penjamu membeli teh terbaik dan dinilai enak oleh tamu, akan kah tamu menganggapnya memuaskan jika teh tersebut tidak dibuat sepenuh hati Rikyu menyarankan bahwa komunikasi hati ke hati antara penjamu dengan tamu dapat melebihi kualitas materil dari teh dan merupakan elemen terpenting dalam memuaskan tamu.

\subsection{2. 炭は湯のわかくように置き，Letakkan arang agar air mendidih＇}

Ajaran ini maksudnya untuk meletakkan arang agar lebih cepat menyala. Meskipun begitu, agar air yang direbus masak dengan efisien, arang harus diletakkan sedemikian rupa agar ada ruang untuk udara masuk. Hal ini dilakukan agar arang dapat menyala dengan baik. Jika arang ditempatkan dengan baik apinya akan cepat padam. Cara bagaimana arang ditempatkan juga menentukan seberapa lama bara akan menyala. Sumidemae, tata cara penataan arang, ada agar api yang dibuat dapat menyala. Namun seperti ajaran pertama, tujuan latihan sumidemae tidak sebatas hanya mempelajari tentang arang dan cara menempatkannya dengan benar, tapi mempelajari tentang arang dan cara menempatkannya dengan benar, tapi mempelajari cara menempatkan hati Anda agar memperhatikan para tamu.

\subsection{3. 花は野の花のように生け, 'Menata bunga seperti di ladang'}

Apakah kecantikan ideal dalam konteks jalan hidup teh? Kata-kata "sebagaimana mereka di padang" mungkin dapat diartikan bahwa mengambil beberapa bunga liar dan 
menaruhnya di vas bunga bagi teh. Rikyu mengajarkan kita bahwa bunga liar yang tumbuh di alam memang indah dan berharga, tapi bunga-bunga untuk teh baru bermakna ketika kecantikan individual dan keberhargaan hidupnya dapat tersampaikan dengan baik dalam karangan.

\subsection{4. 冬は暖に夏は涼しく 'Musim panas sejuk, musim dingin hangat'}

Dalam jalan hidup teh, ada jenis perjamuan teh pagi hari (asa-chaji) untuk menjamu tamu di titik paling panas musim dengan mengundang mereka untuk datang pukul 6 . Tradisi ini bermula dari pandangan positif akan musim panas yaitu ide untuk menikmati hidup saat musim panas dan sejuknya pagi musim ini. Penjamu dapat menggunakan peralatan-peralatan dari kaca untuk mengibaratkan es dan menyajikan manisan yang memberi rasa sejuk. Perjamuan teh pagi hari merupakan cara yang baik untuk mempraktikkan ajaran "menciptakan suasana sejuk". Hal yang sama juga berlaku saat musim dingin, ketika penjamu berusaha "menciptakan suasana hangat". Intinya, ajaran ini mengajarkan pentingnya sensitifitas dan perhatian terhadap tamu serta kemampuan untuk menyusun cara-cara agar para tamu nyaman, baik saat panasnya musim panas atau musim dingin.

\subsection{5. 刻限は早めに 'Selalu berjaga-jaga dalam segala hal'}

Dapat dikatakan jika menepati janji dan mengikuti perjanjian yang disepakati merupakan sikap-sikap dasar yang baik menurut semua orang yang bermasyarakat. Ajaran Rikyu yang satu ini mengajarkan kita jika kita baiknya tidak menunda sesuatu sampai waktuwaktu akhir, bahkan untuk hal-hal sepele. Ini karena kita tidak pernah tahu apa yang akan terjadi setelahnya. Ajaran ini cukup sederhana; meskipun begitu, banyak orang menganggapnya tidak mudah dilaksanakan. Karena sifat waktu kita yang tidak dapat diprediksi, kita perlu memanfaatkan dengan sebaik mungkin waktu yang ada. Pentingnya untuk bekerja secara efisien sering kali ditekankan kini, dan itu berarti kita harus menganggap waktu sebagai hal yang berharga dan menghindarkan diri dari membuang-buangnya. Kenyataan jika ajaran ini telah diajarkan Rikyu berabad-abad lalu membuktikan jika masalah pemanfaatan waktu bukan hanya masalah di era kita saja. 


\subsection{6. 降らずとも雨の用意 'Mempersiapkan payung meskipun hujan tidak turun＇}

Pada masa Rikyu ramalan cuaca tidak ada, dan karena di Jepang sering hujan, sangat sulit memprediksikan kemungkinan hujan. Inti ajaran ini tentu saja tidak sekedar bersikap preventif jika hujan turun, tapi bersiap terhadap segala macam hal tidak terduga. Seperti ajaran-ajaran lain, ajaran ini mungkin terlihat sederhana, namun sulit dipraktikan. Chanoyu begitu menekankan pentingnya mengembangkan ketenangan dalam diri untuk menghadapi semua hal yang mungkin terjadi. Dengan terus mengikuti latihan ini, pengembangan ketenangan diri ini akan dapat terus dilatih hingga akhirya berlangsung dengan sendirinya.

\subsection{7. 相客に心せよ 'Perhatikanlah tamu’}

Dalam riuhnya kehidupan di zaman kita, kata-kata sopan seperti, "maaf sudah mendahului", atau "silakan duluan", semakin jarang terdengar. Saat ini semakin banyak orang berpikir kalau misalkan mereka mendahului seseorang di depan mereka saat antri, meminta maaf sudah tidak perlu dilakukan. Akhir-akhir ini bahkan terdapat kecenderungan untuk meninggalkan sapaan-sapaan harian seperti, "selamat pagi", atau "permisi". Padahal ungkapanungkapan ini merupakan cara yang baik untuk membangun hubungan positif dan nyaman dengan orang lain. Dalam chanoyu, kita mencoba membuka hati kita pada orang lain dan melayani satu sama lain, baik dalam hubungan kita sebagai penjamu dan tamu atau sesama tamu. Dalam ruang teh, kata-kata seperti, "maaf mendahului", "silakan", "saya terima dengan senang hati". Kata-kata ini menunjukkan kesopanan kita terhadap satu sama lain yang juga kita praktikan di luar ruang teh. Ini karena penting bagi kita untuk menumbuhkan sikap sopan dan peduli terhadap sesama sebab kita tidak hidup di dunia ini sendiri. Seperti pepatah yang berbunyi, "perhatian akan dihargai pada akhirnya", marilah kita mulai mencoba memikirkan orang lain. Lewat semangat melayani satu sama lain, dapat mempraktikkan cara untuk mencapai kebahagiaan bersama.

\subsection{Empat Prinsip Utama Semangat Chanoyu}

Genshitsu Sen (2014: 14) menyatakan bahwa semangat inti dari chanoyu terkandung dalam konsep 和, 敬、静、寂（wa, kei, sei, jaku/keselarasan, rasa saing menghargai, kesucian, dan kedamaian). Konsep 4 prinsip utama(四規) sebagai berikut: 
1. “和” wa, berarti keserasian di antara manusia, manusia dengan alam, keserasian dengan peralatan minum teh dengan cara penggunaannya. Pangeran Shoutoku dalam naskah 17 pasal Konstitusi mengawali kalimatnya dengan pernyataan, "keselarasan harus dihargai". Kebijaksanaan yang terkandung dalam pernyataan tersebut adalah bahwa kedamaian sejati akan terwujud ketika tiap orang berlaku dalam semangat keselarasan perdamaian. Hal ini dapat kita katakan sebagai salah satu syarat masyarakat yang sehat.

2. “敬” kei, berarti rasa hormat. Rasa hormat atas segala sesuatunya yang mana berasal dari rasa syukur yang tulus atas keberadaannya. Manusia tidak dapat hidup sendiri, mereka berbaur dengan sesama karena dukungan dan bantuan yang mereka terima satu sama lain. Prinsip "rasa menghargai" ini mengajarkan kita bahwa kita harus memperlakukan orangorang di sekitar dengan rasa menghargai.

3. “清” sei, berarti kemurnian, serta menyiratkan baik kebersihan keduniawian maupun kebersihan hati. Prinsip ini tidak hanya merujuk pada kebersihan dalam hal psikis, namun juga kesucian dalam diri seseorang.. Ketika kita berjalan saat hari sedang hujan, mobil yang lewat mungkin akan mencipratkan lumpur ke pakaian orang yang di pinggir jalan. Namun, lumpur semacam ini dapat dengan mudah dibersihkan. Lain halnya saat hati kita yang ternoda, kotoran yang ada akan lebih sulit dilihat apalagi dibersihkan. Sepert pakaian dan tangan kita yang bisa kotor, hal-hal yang mengotori kehidupan juga dapat bersemayam dalam jiwa kita. Namun, sering kali kita tidak bisa langsung menyadarinya karena kita tidak bisa langsung melihatnya. Hal-hal yang memiliki bentuk konkrit lebih mudah untuk dilihat tapi yang tidak, mungkin lebih sulit disadari keberadaannya walaupun mungkin hal tersebut bukan sesuatu yang baik. Prinsip kesucian menekankan pada ketidaksucian semacam itu dalam diri seseorang. Hal yang paling penting yang harus kita lakukan adalah terus berpikir terbuka dan rendah diri, sambil terus berusaha menyucikan pikiran dan batin.

4. “寂” jaku, berarti ketenangan atau ketenangan pikiran yang datang dari pemahaman atas ketiga prinsip tersebut. Karena kita tidak bisa melihat atau meramal masa depan, kita harus selalu berusaha mempertahankan ketenangan dan keteguhan pikiran sehingga kita bisa siap menghadapi apapun yang mungkin terjadi. Kedamaian dengan kata lain merupakan keadaan pikiran ketika kita telah siap menghadapi semua kemungkinan. 
Hal lain juga diungkapkan oleh Suzuki mengenai sei (kemurnian) sebagai berikut: "Purity", estimated as constituting the spirit of the art of tea, may be said to be contribution of Japanese mentality. Purity is cleanliness or sometimes orderliness, which is observable in everything everywhere concerned with the art. Fresh water is liberally used in the garden (roji), in case natural running water is not available, there is a stone basin filled with water as one approaches the tearoom, which is naturally kept clean and free from dust and dirt (Suzuki, 1991). "Kemurnian", dinilai sebagai perolehan jiwa dari seni minum teh, yang mungkin dinilai sebagai perolehan jiwa dari seni minum teh, yang mungkin bisa dikatakan untuk dapat memberikan kontribusi dari mentalitas orang Jepang. Kemurnian adalah kebersihan atau terkadang sesuatu yang rapi pada segala sesuatu dan segala tempat yang memberikan suatu karya seni. Air segar biasanya digunakan dalam taman (roji), dalam hal ini jika tidak ada air mengalir di taman, maka biasanya terdapat penampung air dari batu yang terisi air yang terhubung ke ruang perjamuan teh, untuk menjaga kebersihan dari debu dan kotoran.

Hubungan "ketenangan" sebagai elemen yang keempat membangkitkan jiwa atau semangat dalam seni teh, dalam karakter China chi atau jaku dalam bahasa Jepang. Jaku adalah sabi. Akan tetapi, sabi mengandung makna lebih dari sekedar "ketenangan". Dapat dikatakan bahwa makna sabi yang sesungguhnya adalah ketenangan, kedamaian, ketenteraman, dan jaku sering digunakan dalam kesusasteraan agama Budha yang merupakan "kematian" atau "nirwana". Dalam hubungan yang dipergunakan pada seni teh, jaku berarti "kemiskinan", "kesederhanaan", dan "kesendirian” (Suzuki, 1991).

\section{Simpulan}

Sebagai penutup dapat disimpulkan sebagai berikut. Pertama nilai filosofis dalam chanoyu tergambar pada tiga bentuk studi melalui disiplin pikiran, perolehan pengetahuan, dan latihan. Selagi menikmati keikutsertaan mereka dalam chanoyu, melalui tiga bentuk studi ini, pelaku chanoyu sepanjang kehidupannya dapat memperdalam pemahaman mereka atas budaya Jepang dan banyak hal lain. Kedua melalui tujuh aturan Sen no Rikyu (shichisoku), dengan memahami implikasi mendalam di balik ajaran-ajaran ini, seseorang akan menyadari bahwa chanoyu merupakan suatu sistem budaya yang memiliki nilai moral dan etika yang tinggi, 
tidak seperti pertunjukkan artistik lain. Ketiga melalui semangat wa, kei, sei, jaku, mengingatkan kita akan prinsip-prinsip keselarasan, rasa menghargai, kesucian, dan kedamaian. Hal yang lebih penting lagi bahwa chanoyu juga mengajarkan kita untuk mempraktikannya, baik ketika sedang menjamu atau sedang menjadi tamu.

\section{Daftar Pustaka}

Burhanuddin, S. (2000). Etika Individual. Jakarta: Asdi Mahasatya.

Driyarkara. (2006). Karya Lengkap Dhiyarkara: Esai-esai Filsafat Pemikir yang Terlibat Penuh dalam Perjuangan Bangsanya. (S. Sudiarja, B. Subanar, Sunardi, \& Sarkim)., Eds.). Jakarta: PT Gramedia Pustaka Utama.

Haidar, B. (2005). Buku Saku Filsafat Islam. Bandung: Mizan.

Kastuti, T. I. (2010). Pemahaman Makna Chadou dengan Dasar Spiritual Senrikyuu melalui Bonryakutemae. Jurnal Sastra Jepang.

Koentjaraningat. (1979). Pengantar Ilmu Antropologi. Jakarta: Aksara Baru.

Plutschow, H. E. (1986). 1986. Historical Chanoyu. Tokyo: The Japan Times, Ltd.

Sen, Genshitsu, \& Soushitsu. (2004). Urasenke Chado Textbook. Kyoto: Tankosha.

Somantri, R. (2014). The Story in A Cup of Tea. Secangkir Kisah Pencinta Teh. Jakarta: Trans Media.

Suseno, F. M. (1992). Filsafat sebagai Ilmu Kritis. Yogyakarta: Kanisius.

Suzuki, D. . (1991). Zen and Japanese Culture. Tokyo: Charles E. Tuttle. Company.

納屋嘉治. (1997). 入門必携. 東京: 財団法人·今日庵. 